\title{
Leukemoid reaction in sarcomatoid type of renal cell carcinoma (SRCC): a rare case report
}

\begin{abstract}
Leukemoid reaction is rarely reported with urinary system related malignancies unlike other solid tumors. Its association with sarcomatoid renal cell carcinoma (SRCC) is even rarer with just two reported cases in a single Chinese case series. With proper work-up, the paraneoplastic leukemoid reaction should be considered after ruling out infectious, iatrogenic or hematologic causes. Paraneoplastic leukemoid reaction is a rare syndrome which seems to be associated with aggressive tumors, rapid clinical deterioration, and short survival. We report a rare presentation of SRCC with leukemoid reaction in a 44-year-old Indian gentleman who died two months after its discovery due to multi-organ failure. This leukemoid reaction did not resolve with surgical intervention. White blood cell count should be closely monitored as an indicator of disease activity in such renal cell carcinoma cases. This paper may contribute to clinical practice when encountering such a patient because of its poor prognostic value.
\end{abstract}

Keywords: paraneoplastic leukemoid reaction, sarcomatoid renal cell carcinoma, cushing's syndrome, computed tomography, epithelial-mesenchymal transition
Volume I Issue I - 2016

\author{
Bhushan MWarpe, Shweta S Joshi \\ Department of Pathology, BKL Walawalkar rural medical college, \\ India
}

Correspondence: Bhushan MWarpe, Department of Pathology, BKL Walawalkar rural medical college, Maharashtra, India, Tel +917030104389, Email bhushan.warpe@gmail.com

Received: October 05, 2016 | Published: November 16, 2016

\section{Introduction}

Renal cell carcinoma ( $\mathrm{RCC}$ ) is called an 'internist's tumor' because it presents with systemic symptoms unrelated to the kidney cancer, such as hypertension (renin), hypercalcemia (PTHrP), polycythemia (erythropoietin), eosinophilia, pyrexia, Cushing's syndrome (ACTH), wasting syndromes, anemia, pyrexia, deranged liver function tests, hypercalcemia and paraneoplastic leukemoid reaction (PLR) due to autonomously produced hormones. ${ }^{1-3}$

Renal cell carcinoma (RCC) accounts for $90 \%$ to $95 \%$ of malignant neoplasms arising from the kidney. ${ }^{1,2}$ Rare finding of sarcomatoid differentiation can occur in all histological subtypes of RCC, with incidence of $1.2 \%$ to $23.6 \%$ and median survival period of two to nine months. ${ }^{2}$ It has been reported that $10-40 \%$ of patients with RCC present PLR symptoms, ${ }^{3}$ but only two SRCC cases have been reported till date with poor prognosis. ${ }^{2}$

Therapy is mainly surgical excision with some benefit of targeted therapy, immunotherapy, radiotherapy, chemotherapy. ${ }^{2,3}$ In spite of surgery, PLR persists in SRCC cases. So PLR can be considered as a tumor marker for SRCC cases which is associated with poor prognosis through systematic work-up. This is the third reported case of SRCC with PLR in world literature and first such Indian case. ${ }^{2}$

\section{Case report}

A 44-years-old Indian gentleman came to a tertiary hospital with complaints of right flank pain, on and off fever, hematuria, burning sensation during micturition since one month. The patient was not diabetic or hypertensive. He did not have any history of substance abuse. There was no bony pain, palpable lymphadenopathy, pulmonary symptoms, upper GI bleed or neurological deficits in this case, thus ruling out the systemic manifestation of metastatic disease.

Physical examination revealed a right-sided tender palpable mass in right loin region. His CT-scan revealed a solid hypo dense right renal lesion measuring 10x10x2 $\mathrm{cm}$ which was suspicious of right malignant renal tumor without distant metastasis. The BMI of the patient was $24.5 \mathrm{~kg} / \mathrm{m}^{2}$. Routine urine examination revealed numerous RBCs and showed pus cells (2-3/hpf) throughout his entire admission tests over the course of two months (Table 1).

Figure 1 shows peripheral smear showing leukemoid reaction. The work-up of the patient included chest X-ray, blood culture, urine culture which were all negative. Serum LDH levels were 1821U/1, LAP score was 310. Widal, dengue, malaria tests were not contributory for his fever. The bone marrow biopsy showed hyper cellular marrow with normoblastic erythropoiesis, increased myeloid series with predominance of metamyelocytes and myelocytes. The myeloid: erythroid ratio was 7:1 with reduced megakaryocytes. No parasites/abnormal tumor cell infiltration/metastasis was noted.

The patient's thyroid function tests, coagulation profile, serum electrolytes were within normal range. The lipid profile showed normal serum VLDL-cholesterol levels with reduced serum levels of total cholesterol, HDL-cholesterol, LDL-cholesterol. His Liver function tests (LFT) was deranged throughout the admission process with reduced levels of serum total proteins, serum albumin, serum globulin and raised levels of serum alkaline phosphatase (452U/l). However bilirubin levels were normal. The serum calcium and phosphorus levels were $9.42 \mathrm{mg} / \mathrm{dl}$ and $3.09 \mathrm{mg} / \mathrm{dl}$ respectively and were normal. His renal function tests showed normal serum levels of creatinine, BUN, uric acid, urea levels except at the time of death wherein he had high serum creatinine levels of $2.5 \mathrm{mg} / \mathrm{dl}$.

With above work-up, the patient was subjected to right radial nephrectomy with regional lymphadenectomy on $19^{\text {th }}$ day of his admission after stabilizing the patient. The histopathologists received right nephrectomy specimen with perirenal fat measuring $15 \times 10 \times 3 \mathrm{~cm}$ (Figure 2). Perirenal fat was adherent to renal cortex especially at tumor area. Renal capsule stripped off easily at most parts but was adherent to tumor at upper pole of kidney. On cut section, the upper 
pole, mid-pole of the kidney showed yellowish fleshy irregular growth measuring $10 \times 10 \times 3 \mathrm{~cm}$, soft to firm with areas of hemorrhage and necrosis. The cortico-medullary distinction was lost at upper pole, mid-pole but was preserved at the lower pole. Grossly, the right adrenal gland was unremarkable.

Sections studied revealed SRCC arising in upper pole of right kidney comprised of malignant spindle cells/sarcomatoid component with features resembling malignant fibrous histiocytoma (Figure 3A) along with minor separate carcinomatous component (Figure 3B). The carcinomatous component was comprised of clear cells and few with eosinophilic cytoplasm arranged in nests, sheets separated by fibro-vascular septa. Profound hemorrhagic necrosis was noted. The tumor infiltrated the adherent renal capsule at places. The peri-

Table I Routine CBC/PS investigations which revealed persistent PLR, from time of detection till unfortunate death nephric fat was uninvolved. The renal hilum showed one lymph node metastasis. The right adrenal gland was uninvolved, unremarkable on microscopic examination.

Sections from specimen labelled as right hilar nodes showed metastases of above malignancy in four out of total four lymphnodes with peri-nodal soft tissue extension. Three out of four lymphnodes in specimen labeled as right paracaval lymphnodes showed metastases. Six out of nine lymphnodes in specimen labeled as inter-aortocaval lymphnodes showed metastases. The final histopathology diagnosis was SRCC with regional lymph-node metastases. This first reported Indian case of SRCC with persistent PLR succumbed to unfortunate death, on 43rd day after surgery.

\begin{tabular}{|c|c|c|c|c|}
\hline $\begin{array}{l}\text { Day from time } \\
\text { of admission }\end{array}$ & $\begin{array}{l}\mathrm{Hb}(\mathbf{G} / \\
\mathrm{DI})\end{array}$ & TLC (Cells/Cumm) & $\begin{array}{l}\text { Platelet } \\
\text { count }(I \\
\text { Cumm) }\end{array}$ & $\begin{array}{l}\text { Findings noted with final diagnosis of leukemoid } \\
\text { reaction }\end{array}$ \\
\hline$\left.\right|^{\text {st }}$ & 8.8 & $\begin{array}{l}27700 \\
\text { (N87\%, LIO\%, EI\%, } \\
\text { M2\%) }\end{array}$ & 588000 & $\begin{array}{l}\text { Moderate microcytic hypo chromic anemia with neutrophilic } \\
\text { leucocytosis, mild left shift in neutrophilic series with } \\
\text { thrombocytosis }\end{array}$ \\
\hline $7^{\text {th }}$ & 7.7 & 26700 & 418000 & $\begin{array}{l}\text { Moderate microcytic hypo chromic anemia with neutrophilic } \\
\text { leucocytosis, mild left shift in neutrophilic series }\end{array}$ \\
\hline $14^{\text {th }}$ & 8.5 & 21000 & 546000 & $\begin{array}{l}\text { Moderate microcytic hypo chromic anemia with neutrophilic } \\
\text { leucocytosis, mild left shift in neutrophilic series with } \\
\text { thrombocytosis after packed cell transfusion }\end{array}$ \\
\hline $19^{\text {th }}$ & Day of su & & & \\
\hline $20^{\text {th }}$ & 8.8 & 40000 & 402000 & $\begin{array}{l}\text { Post-operative day two: Moderate microcytic hypo chromic } \\
\text { anemia with neutrophilic leucocytosis, mild left shift in } \\
\text { neutrophilic series }\end{array}$ \\
\hline $21^{\mathrm{st}}$ & 10.4 & 38000 & 397000 & $\begin{array}{l}\text { Post-operative day three, after further packed cell transfusion: } \\
\text { Mild microcytic hypo chromic anemia with neutrophilic } \\
\text { leucocytosis, mild left shift in neutrophilic series }\end{array}$ \\
\hline $23^{\text {rd }}$ & 10.2 & 46400 & 452000 & $\begin{array}{l}\text { Post-operative day five: Mild microcytic hypo chromic anemia } \\
\text { with neutrophilic leucocytosis, mild left shift in neutrophilic } \\
\text { series }\end{array}$ \\
\hline $31^{\text {st }}$ & 9.3 & 61800 & 633000 & $\begin{array}{l}\text { Post-operative day } \mid 3^{\text {th }} \text { : Moderate microcytic hypo chromic } \\
\text { anemia with neutrophilic leucocytosis, mild left shift in } \\
\text { neutrophilic series with thrombocytosis }\end{array}$ \\
\hline $39^{\text {th }}$ & 7.2 & 63600 & 495000 & $\begin{array}{l}\text { Post-operative day }\left.2\right|^{\text {th: }} \text { Moderate microcytic hypo chromic } \\
\text { anemia with neutrophilic leucocytosis, mild left shift in } \\
\text { neutrophilic series with thrombocytosis }\end{array}$ \\
\hline$\left.4\right|^{s t}$ & 8.3 & 58200 & 452000 & $\begin{array}{l}\text { Post-operative day } 23^{\text {th }} \text { after transfusion: Moderate microcytic } \\
\text { hypo chromic anemia with neutrophilic leucocytosis, mild left } \\
\text { shift in neutrophilic series }\end{array}$ \\
\hline $45^{\text {th }}$ & 8.2 & 56900 & 246000 & $\begin{array}{l}\text { Post-operative day } 27^{\text {th }} \text { : Moderate microcytic hypo chromic } \\
\text { anemia with neutrophilic leucocytosis, mild left shift in } \\
\text { neutrophilic series }\end{array}$ \\
\hline $61^{\text {st }}$ & 4.3 & $\begin{array}{l}46500 \\
\text { (DLC-N86\%, L6\%, E4\%, } \\
\text { M4\%) }\end{array}$ & 61000 & $\begin{array}{l}\text { Post-operative day } 43^{\text {th }} \text {, day of death: } \\
\text { Severe anemia, grade II thrombocytopenia, neutrophilic } \\
\text { leucocytosis, mild left shift in neutrophilic series }\end{array}$ \\
\hline
\end{tabular}




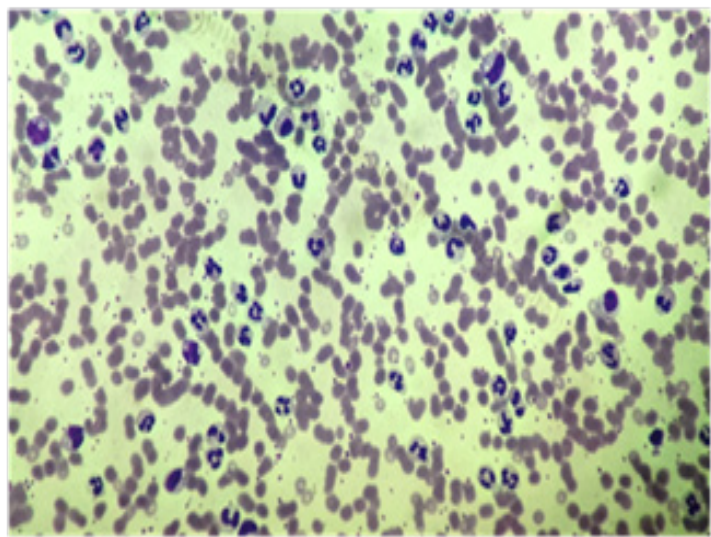

Figure I Shows peripheral smear showing leukemoid reaction with increased mature neutrophils, few band forms (Leishman stain, $x 400$ ).

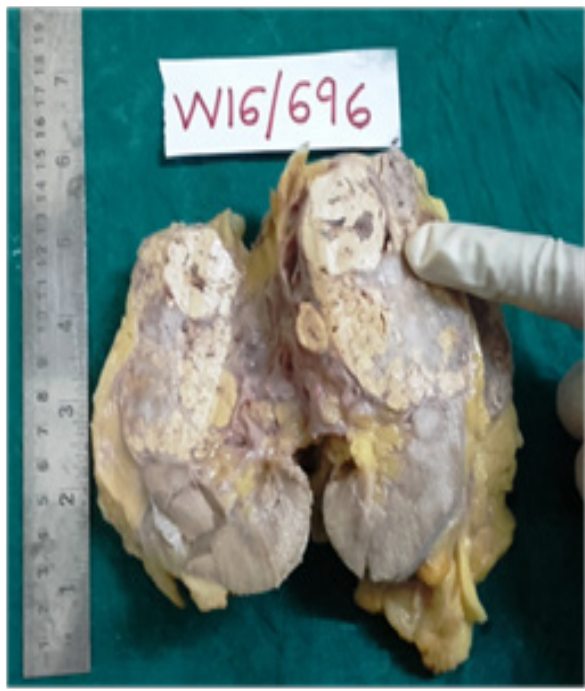

Figure 2 Gross specimen-Cut section of right nephrectomy specimen showing yellowish, fleshy, irregular growth measuring $10 \times 10 \times 3 \mathrm{~cm}$, soft to firm with areas of haemorrhage and necrosis in upper pole and mid pole of the kidney.

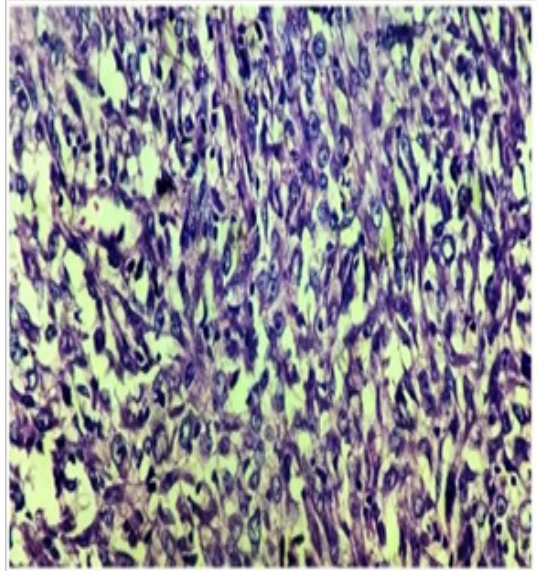

Fig, Ja

Figure 3A Microphotograph-Tumor section shows malignant spindle cells/sarcomatoid component with features resembling malignant fibrous histiocytoma (H\&E, X 400).

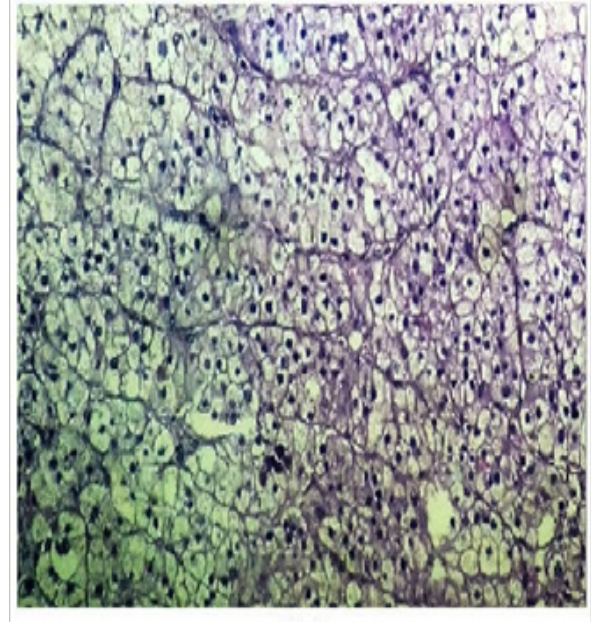

Fig, $3 b$

Figure 3B Microphotograph-tumor section shows adjacent minor, separate carcinomatous component comprised of clear cells and few cells with eosinophilic cytoplasm arranged in nests, sheets separated by fibro-vascular septa (H\&E, X 400).

\section{Discussion}

The classic triad of hematuria, abdominal pain, and a palpable mass is present in $\leq 10 \%$ of RCC cases just like in our case. ${ }^{3}$ Leukemoid reaction, first described by Krumbhaar (1926), is defined as white blood cell count of $>50000$ to 1 lakh/cumm. ${ }^{2,4,5}$ When this is associated with a non-hematological malignant tumor like progressive renal carcinoma, and after ruling out infection, leukemia through proper work-up, it is termed as paraneoplastic leukemoid reaction, according to a Taiwanese study (PLR). ${ }^{5}$ PLR with conventional RCC have been reported by few studies..$^{5-7}$ However PLR with Sarcomatoid type of RCC (SRCC) is very rare with just two cases reported by a single Chinese study, till date. ${ }^{2}$

Appropriate laboratory investigations to arrive at PLR include a complete blood cell count, a comprehensive metabolic panel (including evaluation of serum calcium level, LFT, LDH and serum creatinine levels), LAP score, a coagulation profile, and urinalysis. ${ }^{3}$ We worked up the case accordingly and found deranged LFTs, deranged lipid profile, increased serum alkaline phosphatase, raised serum creatinine just before death, increased serum LDH, increased LAP score apart from leukemoid reaction which persisted throughout the two month admission process and even after the patient's surgery. Hypercalcemia with RCC is most often associated with metastatic bone disease, unlike our case with normal calcium levels without marrow metastasis. ${ }^{3}$

Imaging studies like computed tomography (CT) scans of the abdomen and pelvis (with and without contrast) revealed a right renal tumor with $10 \times 10 \times 2 \mathrm{~cm}$. The median tumor size of SRCC by one study was $10.5 \mathrm{~cm} .{ }^{8}$ Also the same study showed hypo dense SRCC lesion on CT scan in $25 \%$ cases of their study, just like in our case. ${ }^{8}$

Abdominal MRI is used to evaluate tumor extension into the inferior vena cava. ${ }^{3}$ PET is not used to diagnose or follow up kidney cancer in any circumstance. ${ }^{3}$ Both MRI and PET scan were not done in our study. The patient was subjected to therapeutic surgery (right nephrectomy) after proper work-up and after stabilizing the patient. 
The histopathology report revealed the right renal tumor as SRCC with regional lymphnode metastases. PLR in malignancies like SRCC occurs due to autonomous production of G-CSF by the tumor cells which stimulates the marrow cells to produce more mature myeloid cell line like mature neutrophils, just like in our case. ${ }^{2,5}$ PLR persisted in spite of uncomplicated surgery, till the unfortunate death of the patient.

Sarcomatoid renal cell carcinomas (SRCC) are composed of two cell populations. Epithelial-mesenchymal transition (EMT) has been proposed as a mechanism for the development of sarcomatous component (SC) from carcinomatous component (CC). ${ }^{9}$ Because of this, they express both epithelial and mesenchymal markers like cytokeratin (91\%), epithelial membrane antigen (87\%) and vimentin $(100 \%)$. Also one IHC study has targeted G-CSF in tissue blocks of RCC by using monoclonal antibodies. ${ }^{5}$ IHC was not done at our setup due to financial restraints of the patient.

Diagnosis of paraneoplastic leukemoid reaction (PLR) must be arrived at, after proper work up of a suspected case of RCC/SRCC. Such cases of SRCC with PLR have poor prognosis. Thus PLR can be used as a tumor marker for RCC/SRCC cases which is mostly associated with post-surgical death by multi-organ failure within few weeks/months of the surgery.

\section{Informed consent statement}

The patient involved in this study died before the manuscript was written. However data are anonymized not to cause harm to the patient or their families, and risk of identification is low.

\section{Acknowledgements}

None.

\section{Conflict of interest}

The author declares no conflict of interest.

\section{References}

1. Siegel R, Naishadham D, Jemal A. Cancer statistics 2012. CA Cancer J Clin. 2012;62(1):10-29.

2. Weiping Huang, Feng Wang, Yeping Li, et al. Leukemoid reaction in sarcomatoid renal cell carcinoma: a two-case report. World J Surg Oncol. 2014;12:100.

3. Palapattu GS, Kristo B, Rajfer J. Paraneoplastic syndromes in urologic malignancy: the many faces of renal cell carcinoma. Rev Urol Fall. 2002;4(4):163-170.

4. Krumbhaar EB. Leukemoid blood picture in various clinical conditions. Am J Med Sci. 1926;172:519.

5. Wang YC, Yang S, Tzen CY, et al. Renal cell carcinoma producing granulocyte colony-stimulating factor. J Formos Med Assoc. 2006;105(5):414-417.

6. Park TS, Park HY, Lee TY, et al. Leukemoid reaction in a patient with renal cell carcinoma. Korean Journal of Urology. 1988;29(5):830-834.

7. Yang SH, Kwon YH, Kang JG, et al. Leukemoid reaction with renal cell carcinoma. Korean J Urol. 1991;32(3):485-489.

8. Yan Y, Liu L, Zhou J, et al. Clinicopathologic characteristics and prognostic factors of sarcomatoid renal cell carcinoma. J Cancer Res Clin Oncol. 2015;141(2):345-352.

9. Conant JL, Peng Z, Evans MF, et al. Sarcomatoid renal cell carcinoma is an example of epithelial--mesenchymal transition. J Clin Pathol. 2011;64(12):1088-1092. 